\title{
Protagonistas de una ciudadanía global que cambia el mundo
}

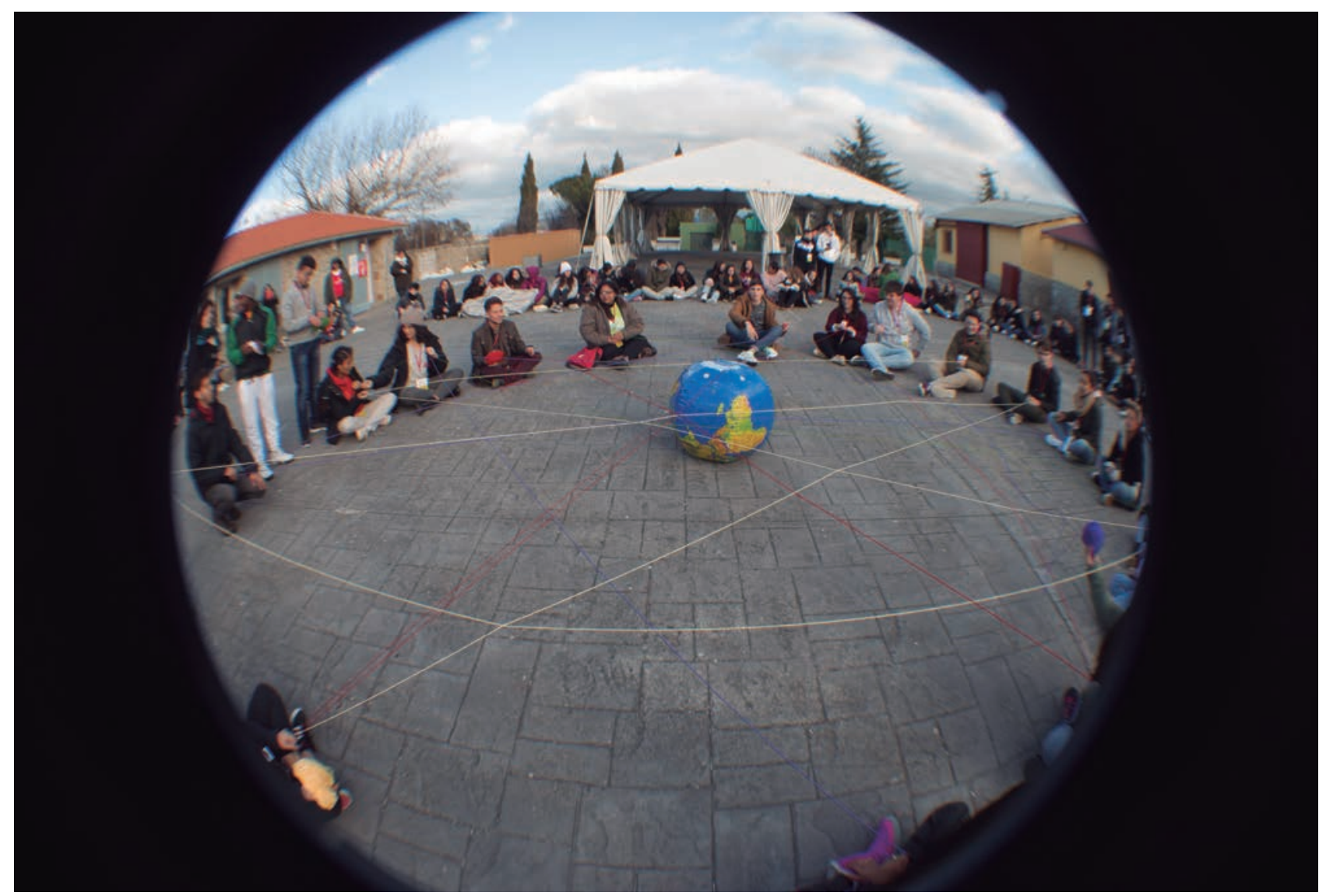

La agenda global que busca construir un mundo más sostenible, pacífico e igualitario necesita del liderazgo de la juventud, que cada vez está más organizada y articulada en una ciudadanía comprometida con la transformación social. Desde movilizaciones internacionales por la igualdad a proyectos de aprendizaje-servicio y encuentros donde las y los jóvenes construyen ciudadanía global, la juventud está tomando el mundo en sus manos como agentes de cambio. 
Cada vez somos más personas conscientes y comprometidas creando un mundo globalmente igualitario, sostenible y pacífico para todas y todos, sin dejar a nadie atrás. Estos últimos años hemos vivido y participado en crecientes acciones ciudadanas por la defensa del medioambiente, la acogida de las personas migrantes y refugiadas, y la construcción de entornos igualitarios y libres de violencias hacia las niñas y las mujeres. Además, cada vez estamos más convencidas y convencidos de de que está en nuestras manos construir este mundo que soñamos desde nuestras acciones locales, trabajando en red con otras personas.

Son las y los jóvenes precisamente las que están impulsando con determinación y creatividad muchos de estos movimientos ciudadanos alrededor del mundo. Con una perspectiva de género transversal que determina cada agenda y acción, vemos que cada vez más grupos de jóvenes en contextos sociales y culturales diversos se están uniendo para poner en agenda ciudadana y política el compromiso que tenemos todas y todos por un mundo más justo, igualitario y sostenible. El desafío y compromiso está en nuestras manos, y miles de jóvenes siguen impulsando acciones desde sus escuelas, barrios, pueblos, ciudades y regiones como parte de una ciudadanía global constructora de un mundo mejor.

Como protagonistas de esta ciudadanía global, Desiré, Tatiana, Juan Andrés y Leydis, participantes de la Red Generación $21+$ de jóvenes, nos comparten sus aprendizajes en procesos de participación juvenil para la transformación social, desde sus acciones en distintos países y regiones. Hablan sobre las claves que consideran necesarias para construir una ciudadanía activa y comprometida, que trabaja en red y que demuestra que es posible transformar el mundo desde lo cercano, lo local, en conexión con otras personas y grupos de jóvenes. Porque los retos a los que nos enfrentamos son globales y urgentes, ellas y ellos ponen énfasis en la necesidad de actuar de la mano como agentes de cambio, tendiendo puentes entre sí, sabiendo que forman parte de una ciudadanía global con metas compartidas.

\section{Desiré Sánchez (España)}

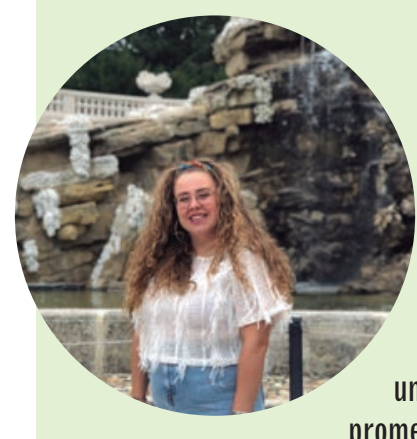

¡Hola! Mi nombre es Desiré, tengo 21 años y soy voluntaria en la Fundación Entreculturas en la ciudad de Valladolid, España.

¿Sabías que, si buscas en internet el término de ciudadanía global, te sale la siguiente definición?: "Corriente social que impulsa un nuevo modelo de ciudadanía comprometido activamente en la consecución de un mundo más equitativo y sostenible".

Ahora bien, ¿qué es para mí la ciudadanía global? Es la manera de apostar por sociedades dialogantes, desaprendiendo lo impuesto socialmente, para poder así construir nuevos diálogos y visiones compartidas. También conlleva la consecución del cambio, transformando esas situaciones o contextos que no nos representan, e intercambiando las actitudes pasivas por activas, sabiendo que los actos de una persona repercuten en otra. Defi- nitivamente es formar parte de una gran masa de personas que quieren un mundo más equitativo y sostenible, ya que el actual no les representa.

De esta manera seguro que muchas personas han participado en un proceso de ciudadanía global sin haber escuchado nunca este nuevo término, como es mi caso. Desde el año 2013 formo parte de Entreculturas, y todo comenzó en el proyecto de la Red Solidaria de Jóvenes, un programa de participación juvenil que se ofrecía al alumnado de manera voluntaria en el centro educativo donde estudiaba. Nos reuníamos los jueves después de las clases y preparábamos actividades dentro del centro educativo. Desde charlas a cursos inferiores hasta tareas específicas dentro de actividades como la Operación Kilo o el Bocadillo Solidario.

Muchas de las cosas que hacíamos cobraban sentido en las asambleas regionales y locales que teníamos. En esos momentos te juntabas con otros jóvenes y profesorado de diferentes centros educativos a dialogar sobre temáticas específicas y te veías reflejada en otras personas, con lo complicado que resulta eso cuando tienes 15 años. Al principio, solo lo vivía como una actividad más 
que nos ofrecía el profesorado, pero a día de hoy lo veo como el comienzo de todo lo que me esperaba y que estoy viviendo ahora, y de las personas que tenía a mi alrededor como ejemplo a seguir.

Actualmente, soy voluntaria en la delegación de Valladolid y partícipe de la Red Generación 21+, una red que une a jóvenes de más de 21 países en las que está presente Fe y Alegría con un mismo compromiso: la transformación social de los territorios donde nos encontramos. Creo que ninguna de las y los jóvenes que conformamos dicha red nos imaginábamos que en países diferentes tendríamos las mismas preguntas, las mismas indignaciones y las mismas ganas por transformar aquellas situaciones que no nos representan, desde la desigualdad social, el daño al medioambiente 0 la inequidad de género.
Hoy en día, si comparase mi desarrollo personal con una planta, diría que un día mis profesoras plantaron una semilla en mí y después otras muchas personas han ido regándola cada día. Gracias a mi participación en dichos procesos hoy soy quien soy. Me han enseñado a tener una visión más crítica de las cosas que me rodean. También, he aprendido a tener nuevos diálogos sobre temas concretos gracias a la formación que he ido recibiendo. He aprendido a ver la belleza de la diversidad cultural a través de la convivencia y el compartir. Pero sobre todo, he encontrado un sitio en el que puedo compartir mis inquietudes, expresar mis ideas sobre ciertos temas y no sentirme juzgada. Además de encontrar una familia que quiere, tanto como yo, luchar por un cambio y conseguir un mundo más equitativo y sostenible.

\section{Tatiana Cardona (Colombia)}

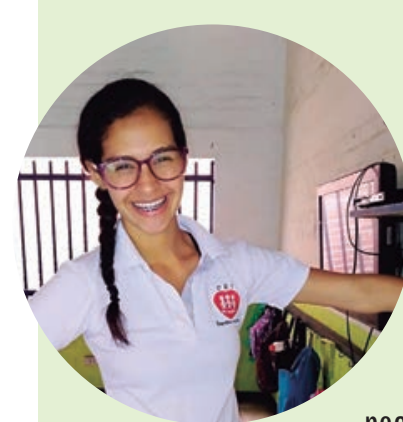

Una ciudadanía global debe estar estrechamente ligada a un compromiso ético, político y ambiental consciente, reconociendo lo que pasa a nuestro alrededor, impulsando a dar soluciones específicas, Esto implica que como personas habitantes de este mundo globalizado nos reivindiquemos y empecemos a sentir, ver, actuar y escuchar los gritos de la humanidad y el Planeta Tierra desesperantes por hacer una transformación desde nosotros como ciudadanos. La ciudadanía global debe entender que la humanidad está por encima de las condiciones geográficas y geopolíticas, que lo global debe ser en primera medida humano. Como mujer joven considero que es importante tener en cuenta tres desafíos para poder incidir en una ciudadanía global: reconocimiento de uno mismo, reconocimiento del otro e incidencia desde lo local a lo global. Por lo tanto, este reconocimiento aumenta en la medida que identifiquemos que nuestros ideales, nuestra historia, ancestros, rasgos culturales y todas esas formas de vivir son diferentes, que no podemos permitir que la globalización nos la arrebate sin resistencia alguna. Cuando entendemos que cada habitante tiene sus propias formas y maneras de vivir, ahí podemos respetar y aprender a vivir juntos en diversidad.

Desde aquí empieza una ciudadanía global humanizada que piensa en la solidaridad, altruismo, justicia e igualdad y sensibilidad social. También es importante entender que para pensar en ciudadanía global no podemos verla como algo inalcanzable, como algo que está muy lejos de nosotros. No seamos más tiempo ciudadanos sordos, ciegos y mudos, aquí y ahora es el momento de empezar a actuar, incidir y transformar. Empieza desde nuestras casas, desde nuestras familias, desde nuestro entorno más cercano, a generar una conciencia colectiva que nos contagie a todos de esa ciudadanía global que juntos queremos construir.

Una experiencia que me ha marcado fue participar en el XLVII Congreso de Fe y Alegría: Educamos en las Fronteras, en España. Al iniciar el viaje, tenía muchas expectativas y emociones encontradas, además de sentirme orgullosa de saber que este sueño empezó en el año 2011, en el centro cultural Abriendo puertas Fe y Alegría a través del arte y la ciudadanía, donde me inicié como participante.

Una parte del encuentro que me conmovió mucho es cuando me hacían las siguientes preguntas: ¿cuéntanos tu experiencia como joven? ¿Desde qué temas trabajas en tu localidad? En este momento sentía que era la oportunidad para expresar todo lo que vengo construyendo y se seguirá construyendo. Siempre expresaba que los jóvenes de Cali trabajamos la ciudadanía desde el arte, desde una visión transformadora que permita entender las expresiones artísticas desde una perspectiva cambiante en la sociedad, que lleve a los demás jóvenes a pensarse la música, las plásticas, el teatro, la danza, entre otras, como una manera de ver, oír, sentir, las dificultades sociales y medioambientales de forma sensible y que genere un pensamiento crítico y de soluciones frente adversidades que nos duelen.

Por esta razón, se hace indispensable que desde cada rincón del mundo se siga fortaleciendo el tema de las juventudes desde sus propias necesidades, intereses o motivaciones, que lleven a procesos juveniles que busquen fortalecer el discurso de la Red Generación 21+: somos actorías políticas, construimos paz para la vida digna, transformamos para incidir y todos juntos somos Fe y Alegría. Este es un reto que se enmarca para el 2019 en la Red, buscando más visibilización y empoderamiento por parte de cada uno de los jóvenes que hacemos parte. Recordemos siempre que somos el aquí y el ahora, y que es momento de actuar. 


\section{Juan Andrés (Colombia)}

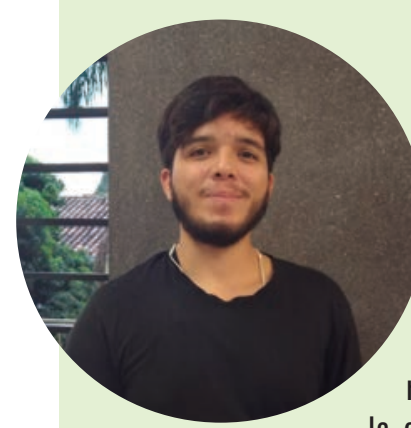

Para mí la ciudadanía global es un concepto amplio y bonito, lo comprendo de manera que nos entendamos a nosotros mismos y a los demás como habitantes de la casa común, sin distinguir raza, lugar de origen, idioma y todas aquellas cosas que nos diferencian culturalmente; partiendo de ello, para mí, la ciudadanía global es aquello que nos mueve a ser conscientes y sensibles de nuestro entorno inmediato y no tan inmediato, que nos permite sensibilizarnos y ser conscientes de la situación de nuestra sociedad y de nuestro planeta, y por ello nos impulsa a buscar el bien y el progreso común. Podría decir que gracias a ella muchas personas son conscientes de temas como el calentamiento global, situación que nos afecta a todos. La ciudadanía también es aquello que nos inspira y nos hace creer, que si unimos esfuerzos podremos hacer algo para mitigar muchas de las problemáticas que como sociedad global nos afectan.

Mi experiencia con la ciudadanía global empieza hace poco más de 3 años, por ese entonces, yo era un joven que no se preocupaba por las problemáticas de mi entorno, pero sí era consciente de ellas. Cuando el proyecto de ParticipAcción Juvenil llegó a mi colegio empecé un proceso de aprendizaje y crecimiento en diferentes ámbitos: empezamos por aprender, desde cómo nosotros podríamos ser agentes de cambio tanto en las personas como en el entorno, cómo influir positivamente en nuestras comunidades y cómo hacer algo al respecto de diferentes cosas que veíamos que no estaban bien. Eventualmente nuestro proceso de aprendizaje se fortaleció, a la vez que la red de jóvenes en la ciudad, haciendo que nuestras acciones fuesen cada vez más sólidas.

Una de estas formas de incidir en nuestras ciudades es nuestro Día de la IndignAcción: desde el 29 de agosto de 2015 los jóvenes de Fe y Alegría Colombia, cada año, pensamos qué nos indigna, nos preguntamos qué está pasando en nuestras ciudades y en nuestro país, en lo que nos produce molestia, y expresamos el deseo de hacer algo al respecto, nos organizamos y aliamos con otros jóvenes, organizaciones y colectivos juveniles para movilizarnos en torno a estas problemáticas. Con todo ello, buscamos no solo mostrar nuestra indignación, sino también enviar un mensaje positivo a las personas. Buscamos hacerles comprender que se puede hacer algo al respecto de todo aquello que no está bien y que no podemos seguir permitiendo; les invitamos a informarse, saber del tema y ser seres sentipensantes.

Todas estas acciones que se desarrollan en nuestras comunidades, en nuestros barrios, en nuestra ciudad, además del día de la IndignAcción y de participar de las agendas territoriales de otros grupos, nos ha llevado a formar lazos de amistad con otros jóvenes que también buscan un horizonte mejor, que apuestan por un cambio desde el trabajo con y para la comunidad. Esto me ha llevado a conocer jóvenes de otras ciudades, chicos y chicas con mucho talento y con visiones del mundo que te llenan el alma, jóvenes líderes y lideresas que cada día transforman sus realidades con acciones pequeñas, una acción a la vez, que en total suman un gran cambio en nuestro país, de una juventud que tiene metas claras y no piensa parar hasta alcanzarlas todas, junto a ello vamos transformando las vidas de nuestras comunidades, porque esto es lo que hacemos: formar para transformarnos y transformarnos para incidir.

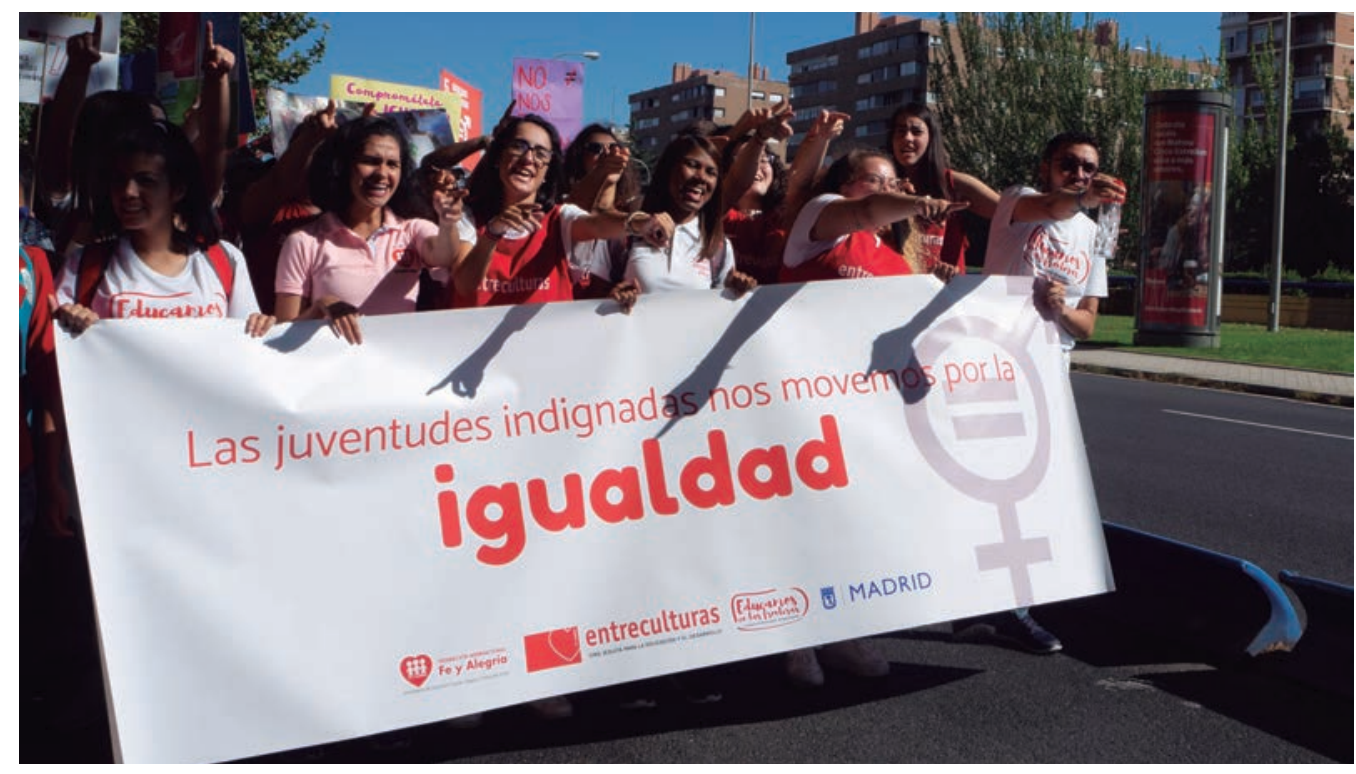




\section{Leydis (Nicaragua)}

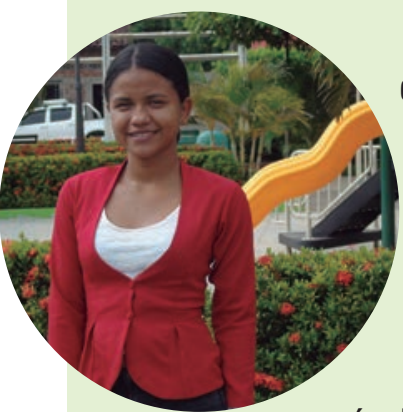

nía global imp

tra propia realidad, conociendo nuestras capacidades y habilidades personales, para emprender un cambio social mediante la realización de alianzas estratégicas con las autoridades locales de nuestras comunidades.

Durante el proceso de participación ciudadana, una de las experiencias que marcó mi vida es el teatro, porque me ayudó a fortalecer mi ciudadanía y también favoreció mi trabajo con las problemáticas de mi contexto de una forma más creativa y dinámica.

Estuve en un proceso de formación en teatro que me permitió la adquisición de conocimientos sobre técnicas de actuación, voz y dicción, vestuario y expresión corporal. Esto me permitió tener la oportunidad de forme parte del grupo de teatro Chico y Chica del Cambio del colegio San Ignacio de Loyola Fe y Alegría en Somotillo (Nicaragua), Siendo un grupo de jóvenes con diversas habilidades como el canto, la danza, los zancos, etc., compartimos la pasión de hacer teatro, desde donde aportamos a un cambio social, donde trabajamos diferentes temáticas como la prevención de la violencia, el cuidado del medioambiente, las migraciones, la equidad de género y la cultura de paz.

Mediante la realización colectiva de obras de teatro aplicando mis conocimientos sobre improvisación y actuación, pudimos sensibilizar a la población de las problemáticas sociales, La experiencia en el teatro me permitió conocerme, darme la oportunidad de conectarme con mi propio interior. Por tanto, también me permitió ser consciente de mi propio cuerpo, lo cual me ayudó a darle lugar a cada sentimiento, como la alegría y la tristeza, identificando mis emociones en diversas situaciones. También el teatro me facilitó la expresión de mis ideas con mayor sencillez, estableciendo relaciones afectivas sanas, que me permitieron fortalecer mi personalidad y defender mis derechos, logrando tener una mayor seguridad y confianza en mí misma.

Hacer teatro me ayudó además a identificar y analizar las problemáticas de mi comunidad, contribuyendo a un cambio social. También ejercí una participación ciudadana más activa, lo que me animó a asistir a otros espacios de reflexiones sobre ciudadanías que nos permitió la elaboración de agendas juveniles, incidencia política con los actores locales, participación en los cabildos municipales, presentación de propuestas de perfiles de proyectos a las autoridades locales como una respuesta a nuestras necesidades en la comunidad, aportando un mayor compromiso ciudadano y estableciendo alianzas estratégicas con las y los actores locales, donde se ejerce la ciudadanía activa, contribuyendo a una transformación social.

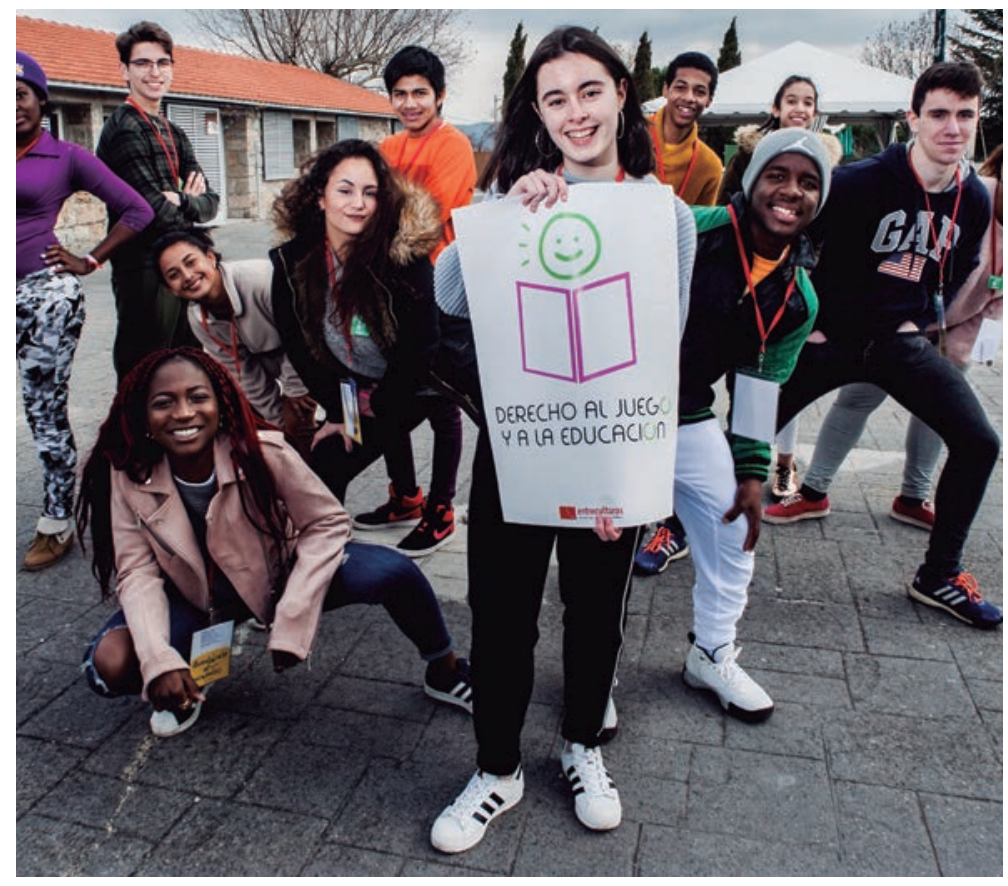

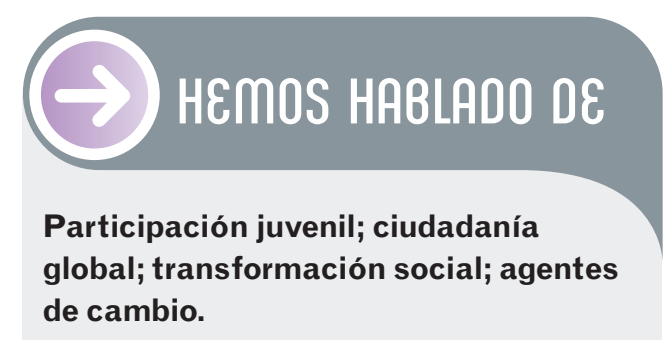

Este artículo fue solicitado por PADRES Y MAESTROS en mayo de 2019, revisado y aceptado en octubre de 2019. 